\title{
Association of Genetic Polymorphisms in Tumour Necrosis Factor-alpha (TNF-a-308G/A) and Interleukin-6 (IL-6-174G/C and IL-6-634C/G) with lung cancer risk: a meta-analysis
}

\section{Yibo Guo}

Henan University of Science and Technology Affiliated First Hospital https://orcid.org/0000-00015461-5084

\section{Xinshuai Wang}

Henan University of Science and Technology Affiliated First Hospital

\section{Xiang Yuan}

Henan University of Science and Technology Affiliated First Hospital

\section{Yiwen Liu}

Henan University of Science and Technology Affiliated First Hospital

\section{Wei Sun}

Henan University of Science and Technology Affiliated First Hospital

Shegan Gao ( $D$ omim123@163.com )

https://orcid.org/0000-0001-6701-4376

Research article

Keywords: Gene Polymorphisms, Tumor necrosis, factor alpha, Interleukin 6, Lung Cancer, Meta analysis

Posted Date: January 13th, 2020

DOI: https://doi.org/10.21203/rs.2.20641/v1

License: (c) (i) This work is licensed under a Creative Commons Attribution 4.0 International License. Read Full License 


\title{
Association of Genetic Polymorphisms in Tumour Necrosis Factor-alpha (TNF- $\alpha-308 G / A)$ and Interleukin-6 (IL-6-174G/C and IL-6-634C/G) with lung cancer risk: a meta-analysis
}

Yibo Guo ${ }^{1}$, Xinshuai Wang ${ }^{2}$, Xiang Yuan ${ }^{l}$, Yiwen Liu ${ }^{1}$, Wei Sun ${ }^{l}$, Shegan Gao ${ }^{1 *}$

\begin{abstract}
Background: Several studies have indicated an association between tumor necrosis factor-alpha (TNF- $\alpha$ ) or interleukin(IL)-6 gene polymorphisms and the risk of lung cancer. However, the conclusions remain controversial.The aim of this study is to examine the association of tumour necrosis factor-alpha (TNF- $\alpha$ ) and interleukin-6 (IL-6) gene polymorphisms with the risk of developing lung cancer.
\end{abstract}

Methods: We searched several electronic databases, including PubMed and Excerpt Medica Database (EMBASE). The effects of three polymorphisms, TNF- $\alpha-308 \mathrm{G} / \mathrm{A}$, IL-6-174G/C and IL-6-634C/G, were evaluated. The pooled odds ratio (OR) with $95 \%$ confidence interval (CI) was calculated by RevMan software. Heterogeneity was also assessed.

Results: For a total of 17 studies involving 4,094 cases and 4,988 controls, were identified in this meta-analysis. Based on our results, we found an association between the TNF- $\alpha-308 \mathrm{G} / \mathrm{A}$ polymorphism and lung cancer risk under the dominant model $(\mathrm{GG}+\mathrm{GA}$ vs. $\mathrm{AA}, \mathrm{OR}=0.60,95 \% \mathrm{CI}$ : 0.40 to 0.89 ). For the IL-6-174G/C polymorphisms, the pooled ORs (95\% CI) of GG/GC vs. CC, GG vs. GC/CC, GC vs. CC, and GG vs. $\mathrm{CC}$ were 1.22 (1.02 to 1.46), 1.22 (1.01 to 1.48), 1.22 (1.01 to 1.48), and 1.12 (0.87 to 1.44$)$, respectively. For the IL-6-634C/G polymorphisms, the pooled ORs (95\% $\mathrm{CI}$ ) of CC/CG vs. GG, CC vs. CG/GG, and C vs. G were 1.04 (0.68 to 1.58 ), 0.69 (0.57 to 0.85), and 0.79 (0.67 to 0.93$)$ respectively.

Conclusions: The results of our analysis of these IL-6 polymorphisms revealed an association between IL-6 and lung cancer risk. This association, however, was not as strong as the association between TNF- $\alpha-308 \mathrm{G} / \mathrm{A}$ polymorphisms and lung cancer risk. Because the current study was limited in sample size, further studies are needed to reveal more precise associations.

Keywords: Gene Polymorphisms; Tumor necrosis factor alpha; Interleukin-6; Lung Cancer; Meta-analysis

\section{Background}

Lung cancer is currently the most common worldwide cause of major cancer-related morbidity and mortality[1]. It is also one of the most fatal malignancies[2]. According to several recent studies, chronic low-grade inflammation is closely related to the incidence of lung cancer. High levels of pro-inflammatory cytokines, such as tumour necrosis factor alpha (TNF- $\alpha$ ) and interleukin-6 (IL-6), have been reported to be directly correlated with several inflammatory diseases, as well as lung

\footnotetext{
1. Henan Key Laboratory of Cancer Epigenetics; Cancer Hospital, The First Affiliated Hospital, College of Clinical Medicine, Medical College of Henan University of Science and Technology, Luoyang, China, 471003;

2. Department of Clinic Laboratory, The First Affiliated Hospital, and College of Clinical Medicine of Henan University of Science and Technology, No.24 Jinghua Road, Luoyang, China, 471003 ※Corresponding author: omim123@163.com
} 
cancer[3].Tumour necrosis factor-alpha is a major inflammatory growth factor that plays a vital role in the regulation of immune and inflammatory responses. Genetic variants of the TNF- $\alpha$ gene may affect the host immune system and correlate with lung cancer risk. As the 308(G/A) polymorphism in the TNF- $\alpha$ promoter region is associated with altered protein levels and transcription rates[4], we explored the relationship between this polymorphism and lung cancer risk. IL-6 is a key pro-inflammatory cytokine that may also play a critical role in carcinogenesis and regulate the expression of several genes involved in inflammation, It is expressed in tumor-infiltrating cells[5]. Hence, we also analysed two polymorphisms in the IL-6 promoter region, $174(\mathrm{G} / \mathrm{C})$ and $634(\mathrm{C} / \mathrm{G})$. Genetic variants, especially functional polymorphisms located in the promoter regions of candidate genes, are known to quantitatively alter gene expression. Although several studies have reported on these IL- 6 and TNF- $\alpha$ gene polymorphisms, the results have been inconsistent and even controversial. We have also not been able to draw conclusions that agree with the existing literature. These discrepancies may arise from a variety of factors, including differences in study populations or the use of small sample sizes. A meta-analysis would thus aid in revealing a more precise association between these gene polymorphisms and lung cancer risk. A stable and reliable conclusion is necessary to unify these inconsistences and provide more conclusive results.

\section{Methods}

\section{Search strategy}

We conducted a systematic literature search of the PubMed database and Excerpta Medica Database (EMBASE) from the earliest available date through October 2015 using the terms "Tumor necrosis factor alpha-308 or TNF-alpha-308 or Interleukin-6 or IL-6" and "Single Nucleotide Gene Polymorphism or SNPs or Nucleotide Gene Polymorphism, Single" and" Lung Cancer or Pulmonary Cancer or Lung Neoplasm" without any language restrictions. In addition, we included a manual search step to add more studies to our reference list. All distinctly irrelevant studies, case reports, editorial comments, and review articles were excluded.

\section{Inclusion criteria and exclusion criteria}

Eligible studies from our literature search had to fulfil the following inclusion criteria: (1) published studies based on case-control designs assessing the association between these gene (TNF- $\alpha-308 \mathrm{G} / \mathrm{A}$ or IL-6-174G/C or IL-6-634C/G) polymorphisms and lung cancer risk, (2) case-control studies based on unrelated individuals, and (3) studies reporting sufficient sample sizes, distributions of alleles, genotype frequency data, and other information. Studies were excluded for the following reasons: (1) the study did not pertain to gene polymorphisms, (2) the study had insufficient information for data extraction and (3) the study was not conducted in humans. If a study reported results from different ethnicities, we treated those ethnicities independently.

\section{Quality Assessment}

Two authors independently assessed the quality of every imported article according to a trial quality tool, which was adapted from existing quality tools, was used to divide the trials into four quality categories : A. low risk of bias in the randomization process; B. moderate risk of bias; C. high risk of bias; D. insufficient information to score allocation concealment. Quality assessments were conducted and evaluated by 5 reviewers. 


\section{Data extraction}

Data were extracted independently by two reviewers based on the inclusion criteria listed above. Any inconsistencies were discussed, and consensus was reached. The following data were obtained: name of first author, year of publication, site of original research, ethnicity of the population, number of patient cases, number of controls, type of controls, method of genotyping, and whether the gene distribution of the controls was in compliance with Hardy-Weinberg Equilibrium (HWE). This information is reported in Tables 1 and 2.

\section{Statistical analyses}

RevMan software (Review Manager, Version 5.3 for Windows, The Cochrane Collaboration, Oxford, UK, 2014) was used for the statistical analyses. Pooled odds ratios (ORs) and 95\% confidence intervals (CI) were calculated for the five gene comparisons (homozygote comparison, heterozygote comparison, dominant model, and recessive model and allele model) and used to assess the associations between TNF- $\alpha-308 G / A$, IL-6-174G/C or IL-6-634C/G polymorphisms and lung cancer risk. Moreover,

422 articles were identified through database searches

\section{3 articles were identified through} other sources

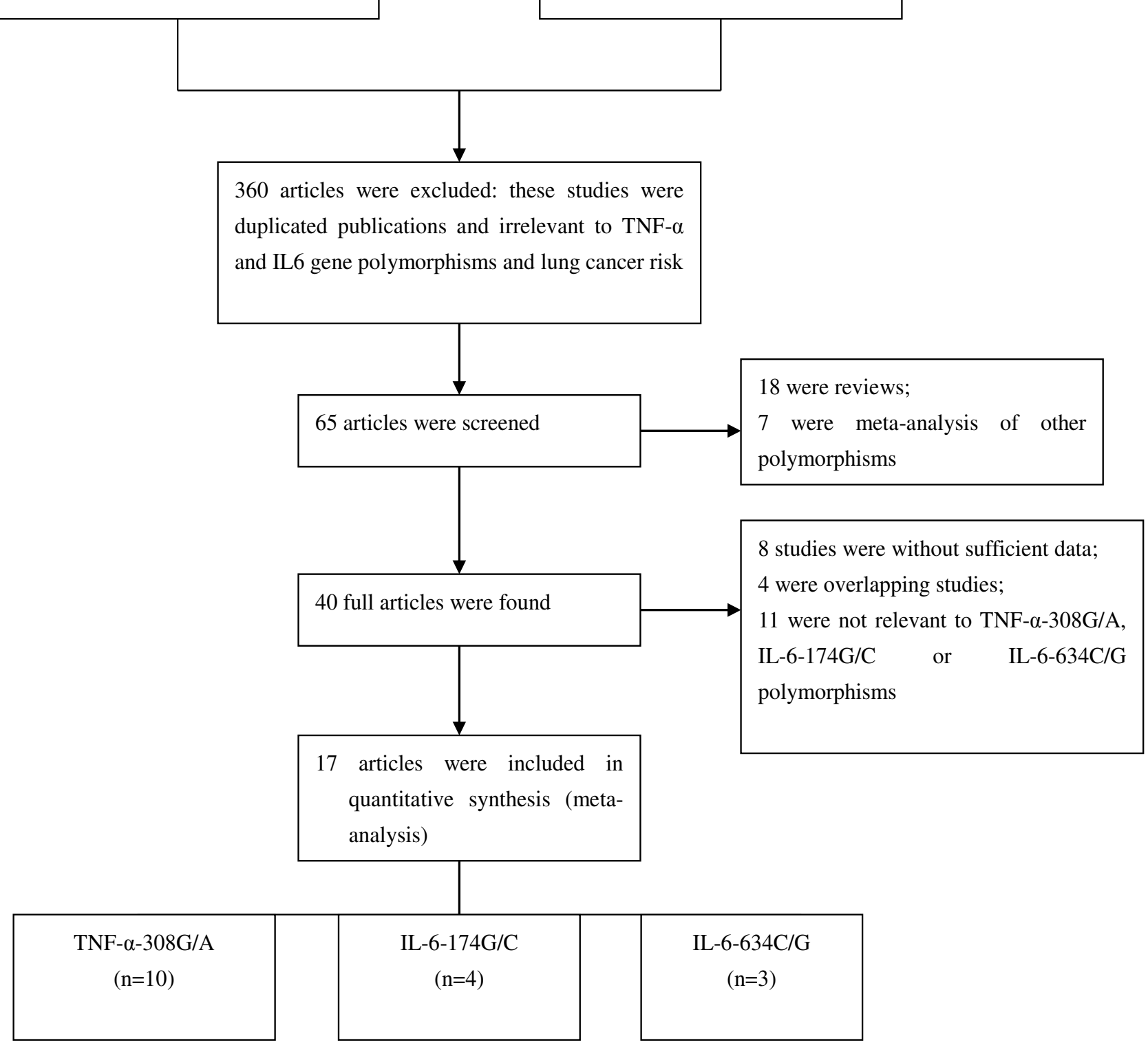

Fig. 1 Flow chart for literature screening. TNF- $\alpha$ : tumor necrosis factor-alpha; IL: Interleukin. 


\begin{tabular}{|c|c|c|c|c|c|c|c|c|}
\hline \multirow{2}{*}{ First author } & \multirow{2}{*}{ Year } & \multirow{2}{*}{ Country } & \multirow{2}{*}{ Ethnicity } & \multirow{2}{*}{ Polymorphisms } & \multicolumn{2}{|c|}{ Sample size } & \multirow{2}{*}{ Method } & \multirow{2}{*}{ HWE } \\
\hline & & & & & cases & controls & & \\
\hline Shih & 2006 & China & Asian & TNF- $\alpha-308 \mathrm{G} / \mathrm{A}$ & 202 & 205 & PCR-RELP & Yes \\
\hline Stankovic & 2009 & Serbia & European & TNF- $\alpha-308 \mathrm{G} / \mathrm{A}$ & 70 & 102 & PCR-RELP & Yes \\
\hline Flego & 2009 & Croatia & European & TNF- $\alpha-308 \mathrm{G} / \mathrm{A}$ & 230 & 230 & PCR-RELP & Yes \\
\hline Reyes-Gibby & 2009 & America & Caucasians & TNF- $\alpha-308 \mathrm{G} / \mathrm{A}$ & 103 & 566 & TaqMan & Yes \\
\hline Flego & 2013 & Croatia & European & TNF- $\alpha-308 \mathrm{G} / \mathrm{A}$ & 305 & 230 & PCR-RELP & Yes \\
\hline Shukla & 2012 & India & Asian & TNF- $\alpha-308 \mathrm{G}>\mathrm{A}$ & 208 & 204 & PCR-RELP & Yes \\
\hline Küçükaycan & 2002 & Netherlands & Caucasian & TNF- $\alpha-308 \mathrm{G} / \mathrm{A}$ & 163 & 335 & PCR & Yes \\
\hline SAFA KAABACHI & 2013 & Tunisia & African & TNF- $\alpha-308 \mathrm{G} / \mathrm{A}$ & 133 & 174 & PCR-RELP & Yes \\
\hline Reyes-Gibby & 2007 & America & $\begin{array}{c}\text { Caucasian } \\
\text { African-Americans } \\
\text { European }\end{array}$ & $\begin{array}{c}\text { TNF- } \alpha-308 \mathrm{G} / \mathrm{A} \\
\mathrm{IL}-6-174 \mathrm{G} / \mathrm{C}\end{array}$ & 482 & 121 & TaqMan & Yes \\
\hline Carola Seifart & 2005 & Germany & European & $\begin{array}{l}\text { TNF- } \alpha 308 \mathrm{G} / \mathrm{A} \\
\text { IL-6-174G/C }\end{array}$ & 117 & 243 & PCR-RELP & Yes \\
\hline Ulla Vogel & 2007 & Denmark & European & IL-6-174G/C & 403 & 744 & PCR & Yes \\
\hline Chikako Kiyohara & 2013 & Japan & Asian & IL-6-174G/C & 462 & 379 & TaqMan & Yes \\
\hline Lu Bai & 2013 & China & Asian & IL-6-634C/G & 193 & 211 & TaqMan & Yes \\
\hline Adeline Seow [7] & 2005 & Singapore & Asian & IL-6-634C/G & 126 & 162 & PCR & Yes \\
\hline Wei-Yen Lim[1][8] & 2011 & Singapore & Asian & IL-6-634C/G & 298 & 718 & PCR & Yes \\
\hline
\end{tabular}

TNF: tumor necrosis factor; IL: interleukin; PCR: polymerase chain reaction; PCR-RFLP: polymerase chain reaction-restriction fragment length polymorphism; HWE: Hardy-Weinberg Equilibrium. 
Table 2 Distribution of genotypes and alleles for TNF- $\alpha-308 G / A$ and IL-6-174G/C and IL-6-634C/G

\begin{tabular}{|c|c|c|c|c|c|c|c|c|c|c|c|c|}
\hline \multirow[t]{2}{*}{ Locus } & \multirow[t]{2}{*}{ Research } & \multirow[t]{2}{*}{ Year } & \multicolumn{3}{|c|}{ Number of cases } & \multicolumn{3}{|c|}{ Number of controls } & \multicolumn{2}{|c|}{ Number of cases } & \multicolumn{2}{|c|}{ Number of controls } \\
\hline & & & GG & GA & $\mathbf{A A}$ & GG & GA & $\mathbf{A A}$ & $\mathbf{G}$ & $\mathbf{A}$ & G & $\mathbf{A}$ \\
\hline \multirow[t]{11}{*}{ TNF- $\alpha-308 \mathrm{G} / \mathrm{A}$} & Shih & 2006 & 110 & 75 & 15 & 169 & 34 & 2 & 295 & 105 & 372 & 38 \\
\hline & Stankovic & 2009 & 57 & 13 & 0 & 71 & 28 & 3 & 127 & 13 & 170 & 34 \\
\hline & Flego & 2009 & 169 & 52 & 9 & 171 & 53 & 6 & 390 & 70 & 395 & 65 \\
\hline & Reyes-Gibby & 2009 & 64 & 34 & 5 & 398 & 155 & 13 & 162 & 44 & 951 & 181 \\
\hline & Flego & 2013 & 219 & 72 & 14 & 171 & 53 & 6 & 510 & 100 & 395 & 65 \\
\hline & Shukla & 2012 & 159 & 41 & 0 & 178 & 30 & 0 & 359 & 49 & 386 & 30 \\
\hline & Küçükaycan & 2002 & 113 & 39 & 1 & 237 & 91 & 7 & 265 & 41 & 565 & 105 \\
\hline & SAFA KAABACHI & 2013 & 73 & 50 & 10 & 142 & 29 & 3 & 196 & 70 & 313 & 35 \\
\hline & Reyes-Gibby & 2007 & 341 & 128 & 13 & 83 & 33 & 5 & 810 & 154 & 199 & 43 \\
\hline & Carola Seifart & 2005 & 80 & 36 & 1 & 171 & 67 & 4 & 196 & 38 & 409 & 75 \\
\hline & & & GG & GC & $\mathbf{C C}$ & GG & GC & $\mathrm{CC}$ & $\mathbf{G}$ & $\mathbf{C}$ & $\mathbf{G}$ & $\mathbf{C}$ \\
\hline \multirow[t]{5}{*}{ IL-6-174G/C } & Ulla Vogel & 2007 & 105 & 202 & 96 & 204 & 361 & 179 & 412 & 394 & 769 & 719 \\
\hline & Carola Seifart & 2005 & 47 & 52 & 17 & 90 & 107 & 46 & 146 & 86 & 287 & 199 \\
\hline & Chikako Kiyohara & 2013 & 28 & 175 & 259 & 13 & 116 & 250 & 231 & 693 & 142 & 616 \\
\hline & Reyes-Gibby & 2007 & 231 & 189 & 61 & 62 & 44 & 14 & 651 & 311 & 168 & 72 \\
\hline & & & $\mathrm{CC}$ & CG & GG & $\mathrm{CC}$ & CG & GG & $\mathrm{C}$ & G & $\mathbf{C}$ & G \\
\hline \multirow[t]{3}{*}{ IL-6-634C/G } & Lu Bai & 2013 & 86 & 89 & 18 & 125 & 69 & 16 & 261 & 125 & 319 & 101 \\
\hline & Adeline Seow & 2005 & 70 & 46 & 8 & 97 & 55 & 10 & 186 & 62 & 249 & 75 \\
\hline & Wei-Yen Lim & 2011 & 163 & 123 & 12 & 449 & 231 & 38 & 449 & 147 & 1129 & 307 \\
\hline
\end{tabular}

TNF: tumour necrosis factor; IL:interleukin. 
heterogeneity was measured by the Chi-square $\mathrm{Q}$ statistic. If the result of the $\mathrm{Q}$ test was $\mathrm{P}_{\mathrm{Q}}<0.05$ or $\mathrm{I}^{2}$ $\geq 50 \%$ (indicating the presence of heterogeneity), a random-effects model was used to estimate the OR. Otherwise, a fixed-effects model was used. Subgroup analyses were conducted according to race distribution to explore the reasons for heterogeneity. Moreover, To explore the impact of single article on the overall estimate, sensitivity analysis was performed by sequential omission of individual studies.

\section{Results}

\section{Characteristics of the included studies}

The process of screening articles is shown in Figure 1. A total of 425 studies were identified after an initial search followed by a manual search. There were 360 duplicated publications. Obvious irrelevant studies were excluded. Eighteen reviews and 7 meta-analyses of other polymorphisms were excluded after review of the titles and abstracts of all articles. After reading the full text of the 40 remaining studies (based on the previously described inclusion and exclusion criteria), 8 articles were excluded for lacking sufficient data, 4 were found to be overlapping studies, and 11 were irrelevant to the TNF-alpha-308 G/A or IL-6-174 G/C or IL-6-634 C/G polymorphisms. Ultimately, 17 relevant articles were included in the meta-analysis. Ten articles pertained to TNF- $\alpha-308 \mathrm{G} / \mathrm{A}, 4$ pertained to IL-6-174G/C, and 3 pertained to IL-6-634C/G. The genotype distributions of all of the included articles were consistent with HWE $(\mathrm{p}<0.05)$.

\section{Association between the TNF- $\alpha-308 G / A$ polymorphism and lung cancer risk}

As shown in Table 3, ten studies including a total of 2013 patient cases and 2410 controls were selected to evaluate the association between TNF- $\alpha-308 \mathrm{G} / \mathrm{A}$ and lung cancer risk. The results revealed that the TNF- $\alpha-308 \mathrm{G} / \mathrm{A}$ polymorphism is associated with an increased risk of lung cancer under five comparison models: dominant model (GG+GA vs. $\mathrm{AA}, \mathrm{OR}=0.60,95 \% \mathrm{CI}: 0.40$ to $0.89, \mathrm{P}=0.01$ ), recessive model ( $\mathrm{GG}$ vs. $\mathrm{GA}+\mathrm{AA}, \mathrm{OR}=0.75,95 \% \mathrm{CI}$ : 0.52 to $1.06, \mathrm{P}=0.10$ ), heterozygous genotype comparison (GA vs. AA, $\mathrm{OR}=0.77,95 \% \mathrm{CI}$ : 0.50 to $1.18, \mathrm{P}=0.23$ ), homozygous genotype comparison (GG vs. AA, $\mathrm{OR}=0.61,95 \% \mathrm{CI}$ : 0.30 to $1.28, \mathrm{P}=0.19)$ and allele comparison $(\mathrm{G}$ vs. A, $\mathrm{OR}=0.76,95 \% \mathrm{CI}: 0.54$ to $1.05, \mathrm{P}=0.10)$. The forest plot for the dominant model of TNF- $\alpha-308 \mathrm{G} / \mathrm{A}$ is shown in Figure 2.

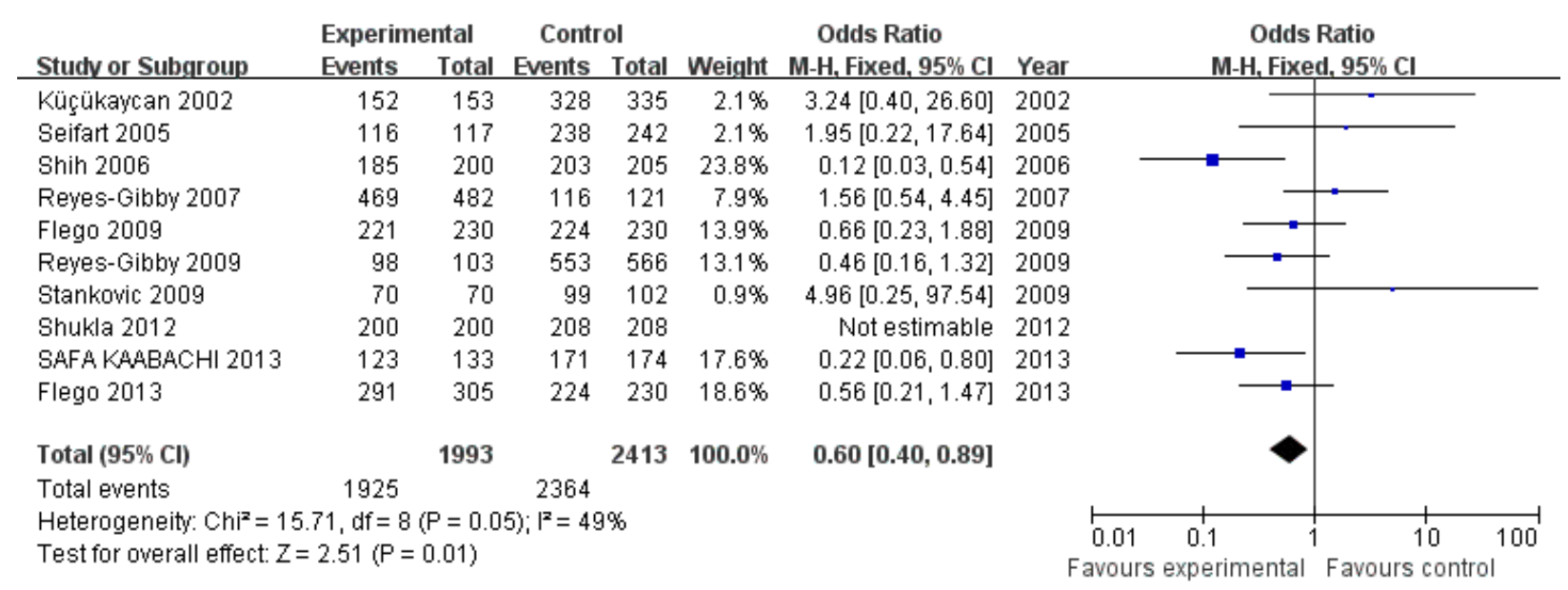

Fig. 2 Forest plots of the association between the TNF- $\alpha-308 G / A$ gene polymorphisms and risk of lung cancer under dominant model (contrast GG + GA vs. AA). OR: odds ratio; CI: confidence interval; TNF- $\alpha$ : tumor necrosis factor-alpha. 
Table 3 Main results of the meta-analysis

\begin{tabular}{|c|c|c|c|c|c|c|c|c|c|}
\hline Locus & Number of studies & Comparison & & Test of & ciation & & $P_{Q}$ value & $\mathbf{I}^{2}(\%)$ & Model \\
\hline \multirow{6}{*}{ TNF- $\alpha-308 \mathrm{G} / \mathrm{A}$} & & & OR & $95 \% \mathrm{CI}$ & $P_{A}$ value & $\mathbf{Z}$ & & & \\
\hline & 10 & $\mathrm{GG}+\mathrm{GA}$ vs. $\mathrm{AA}$ & 0.6 & $0.40-0.89$ & 0.01 & 2.51 & 0.05 & 49 & $\mathrm{~F}$ \\
\hline & 10 & GG vs. $\mathrm{GA}+\mathrm{AA}$ & 0.75 & $0.52-1.06$ & 0.1 & 1.62 & 0.0001 & 83 & $\mathrm{R}$ \\
\hline & 10 & GA vs. AA & 0.77 & $0.50-1.18$ & 0.23 & 1.21 & 0.52 & 0 & $\mathrm{~F}$ \\
\hline & 10 & GG vs. AA & 0.61 & $0.30-1.28$ & 0.19 & 1.31 & 0.01 & 60 & $\mathrm{R}$ \\
\hline & 10 & G vs. A & 0.76 & $0.54-1.05$ & 0.1 & 1.65 & 0.0001 & 85 & $\mathrm{R}$ \\
\hline \multirow{4}{*}{ IL-6-174G/C } & 4 & GG vs. $\mathrm{GC}+\mathrm{CC}$ & 1.01 & $0.83-1.23$ & 0.91 & 0.11 & 0.24 & 28 & $\mathrm{~F}$ \\
\hline & 4 & GC vs. $\mathrm{CC}$ & 1.22 & $1.01-1.48$ & 0.04 & 2.07 & 0.41 & 0 & $\mathrm{~F}$ \\
\hline & 4 & GG vs. CC & 1.12 & $0.87-1.44$ & 0.38 & 0.89 & 0.16 & 41 & $\mathrm{~F}$ \\
\hline & 4 & G vs. C & 1.11 & $0.89-1.37$ & 0.36 & 0.92 & 0.03 & 66 & $\mathrm{R}$ \\
\hline \multirow[t]{4}{*}{ IL-6-634C/G } & 3 & $\mathrm{CC}+\mathrm{CG}$ vs. $\mathrm{GG}$ & 1.04 & $0.68-1.58$ & 0.87 & 0.16 & 0.58 & 0 & $\mathrm{~F}$ \\
\hline & 3 & $\mathrm{CC}$ vs. $\mathrm{CG}+\mathrm{GG}$ & 0.69 & $0.57-0.85$ & 0.0004 & 3.52 & 0.31 & 15 & $\mathrm{~F}$ \\
\hline & 3 & CG vs. GG & 1.34 & $0.86-2.10$ & 0.2 & 1.29 & 0.66 & 0 & $\mathrm{~F}$ \\
\hline & 3 & C vs. G & 0.79 & $0.67-0.93$ & 0.005 & 2.81 & 0.38 & 0 & $\mathrm{~F}$ \\
\hline
\end{tabular}

OR: odds ratio; CI: confidence interval; $\mathrm{F}$ : fixed-effects model; R: random-effects model. $\mathrm{P}_{\mathrm{A}}$ : $\mathrm{P}$ value for test of the association; $\mathrm{P}_{\mathrm{Q}}: \mathrm{P}$ value for between study heterogeneity. 


\section{Association between the IL-6-174G/C polymorphism and lung cancer risk}

We identified four studies that investigated the association between the IL-6-174G/C polymorphism and lung cancer risk, which included 1464 patient cases and 1487 controls, using five different comparisons: dominant model (GG+GC vs. $\mathrm{CC}, \mathrm{OR}=1.22,95 \% \mathrm{CI}: 1.02$ to $1.46, \mathrm{P}=0.03$ ), recessive model ( $\mathrm{GG}$ vs. $\mathrm{GC}+\mathrm{CC}, \mathrm{OR}=1.01,95 \% \mathrm{CI}: 0.83$ to $1.23, \mathrm{P}=0.91$ ), heterozygous genotype comparison ( $\mathrm{GC}$ vs. $\mathrm{CC}, \mathrm{OR}=1.22,95 \% \mathrm{CI}: 1.01$ to $1.48, \mathrm{P}=0.04$ ), homozygous genotype comparison (GG vs. $\mathrm{CC}, \mathrm{OR}=1.12,95 \% \mathrm{CI}$ : 0.87 to $1.44, \mathrm{P}=0.38$ ) and allele comparison ( $\mathrm{G}$ vs. $\mathrm{C}$, $\mathrm{OR}=1.11,95 \% \mathrm{CI}: 0.89$ to $1.37, \mathrm{P}=0.36$ ). The results are shown in Table 3 . The forest plot for the dominant model of IL-6-174G/C is shown in Figure 3.

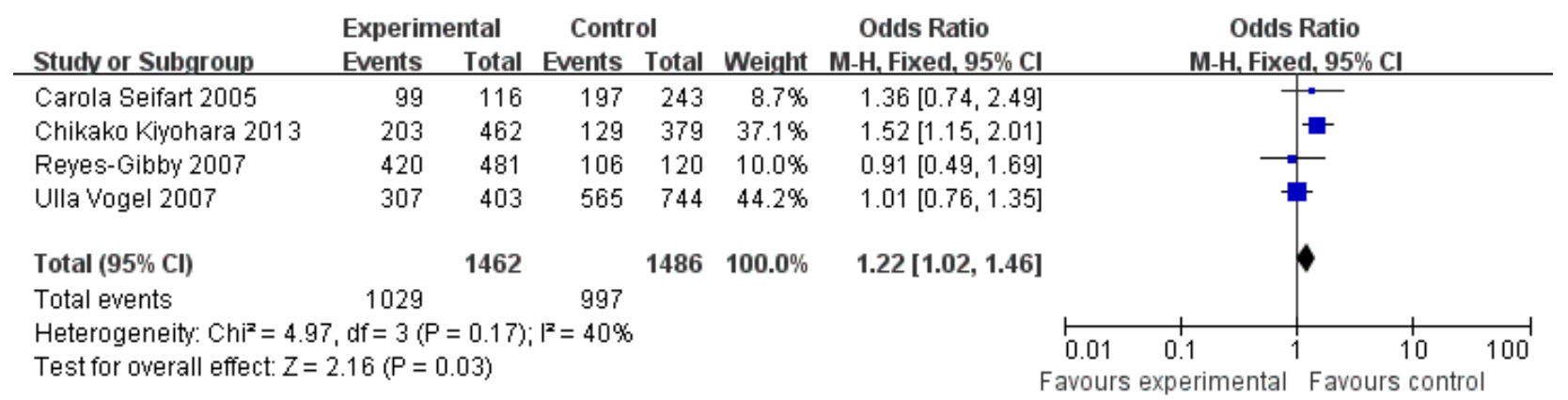

Fig. 3 Forest plots of the association between the IL-6-174G/C gene polymorphisms and risk of lung cancer under dominant model (contrast GG+GC vs. CC). OR: odds ratio; CI: confidence interval; IL: Interleukin

\section{Association between the IL-6-634C/G polymorphism and lung cancer risk}

We identified a single article that included three studies with a total of 617 patient cases and 1,091 controls that investigated the association between the IL-6-634C/G polymorphism and lung cancer risk. All of the studies were carried out in Europe. Our analysis is shown in Table 3, and the results of the five comparisons are as follows: dominant model (CC + CG vs. GG, OR $=1.04,95 \%$ CI: 0.68 to 1.58 , $\mathrm{P}=0.87$ ), recessive model ( $\mathrm{CC}$ vs. $\mathrm{CG}+\mathrm{GG}, \mathrm{OR}=0.69,95 \% \mathrm{CI}$ : 0.57 to $0.85, \mathrm{P}=0.0004$ ), heterozygous genotype comparison ( $\mathrm{CG}$ vs. $\mathrm{GG}, \mathrm{OR}=1.34,95 \% \mathrm{CI}: 0.86$ to $2.10, \mathrm{P}=0.20$ ), homozygous genotype comparison ( $\mathrm{CC}$ vs. $\mathrm{GG}, \mathrm{OR}=0.87,95 \% \mathrm{CI}: 0.56$ to $1.35, \mathrm{P}=0.54$ ) and allele comparison ( $\mathrm{C}$ vs. $\mathrm{G}, \mathrm{OR}=0.79,95 \% \mathrm{CI}: 0.67$ to $0.93, \mathrm{P}=0.005$ ). The forest plot for the recessive model of IL-6-634C/G is shown in Figure 4.

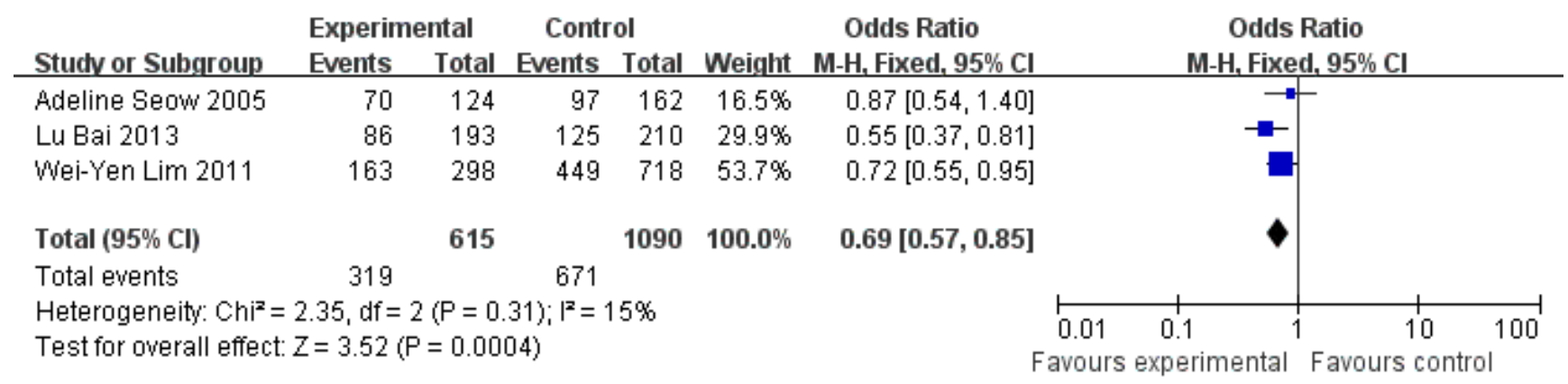

Fig. 4 Forest plots of the association between the IL-6-634C/G gene polymorphisms and risk of lung cancer under recessive model (contrast CC vs. CG + GG). OR: odds ratio; CI: confidence interval; IL: Interleukin 
Table 4 The results of the subgroup analyses

\begin{tabular}{|c|c|c|c|c|c|}
\hline \multirow{2}{*}{ Gene polymorphism } & \multirow{2}{*}{ Comparison } & \multicolumn{4}{|c|}{ OR (95\% CI) } \\
\hline & & Asian & European & Caucasians & African \\
\hline \multirow[t]{5}{*}{ TNF- $\alpha-308 \mathrm{G} / \mathrm{A}$} & GG + GA vs. AA & $0.12[0.03,0.54]$ & $0.79[0.42,1.48]$ & $1.01[0.47,2.19]$ & $0.39[0.14,1.08]$ \\
\hline & GG vs. $\mathrm{GA}+\mathrm{AA}$ & $0.39[0.28,0.54]$ & $0.97[0.77,1.22]$ & $0.97[0.74,1.26]$ & $0.44[0.29,0.68]$ \\
\hline & GA vs. AA & $0.29[0.06,1.36]$ & $0.79[0.41,1.53]$ & $1.05[0.48,2.32]$ & $0.63[0.21,1.92]$ \\
\hline & GG vs. AA & $0.09[0.02,0.39]$ & $0.79[0.43,1.48]$ & $1.00[0.46,2.18]$ & $0.33[0.12,0.91]$ \\
\hline & G vs. A & $0.38[0.28,0.51]$ & $0.96[0.78,1.17]$ & $0.98[0.77,1.23]$ & $0.47[0.33,0.69]$ \\
\hline \multirow[t]{5}{*}{ IL-6-174G/C } & $\mathrm{GG}+\mathrm{GC}$ vs. $\mathrm{CC}$ & $1.52[1.15,2.01]$ & $1.07[0.83,1.38]$ & $1.17[0.61,2.22]$ & NA \\
\hline & $\mathrm{GG}$ vs. $\mathrm{GC}+\mathrm{CC}$ & $1.82[0.93,3.56]$ & $0.99[0.78,1.25]$ & $1.25[0.74,2.12]$ & $0.92[0.33,2.63]$ \\
\hline & GC vs. CC & $1.46[1.09,1.95]$ & $1.09[0.83,1.43]$ & $1.06[0.54,2.11]$ & NA \\
\hline & GG vs. CC & $2.08[1.05,4.11]$ & $1.04[0.77,1.41]$ & $1.31[0.64,2.70]$ & NA \\
\hline & G vs. C & $1.45[1.14,1.83]$ & $1.02[0.88,1.18]$ & $1.17[0.82,1.66]$ & $0.93[0.34,2.52]$ \\
\hline
\end{tabular}




\section{Subgroup analysis}

We conducted further subgroup analyses based on ethnicity. All of the subgroup results are shown in Table 4. Two studies on the TNF- $\alpha-308 \mathrm{G} / \mathrm{A}$ polymorphism $[9,10]$ were conducted in Asian cohorts, five $[11,12,13,14,15]$ were conducted in European cohorts, three were conducted in [13,16,17]Caucasian cohorts, and two $[13,18]$ were conducted in African cohorts. Our meta-analysis revealed a statistically significant association between the TNF- $\alpha-308 \mathrm{G} / \mathrm{A}$ polymorphism and lung cancer risk in Asians. Among the IL-6-174G/C studies, one [13]was conducted in Caucasian and African cohorts; one [19], in Asian cohorts; and the remaining [13,14,20], in European cohorts. Similarly, we found a significant relationship between IL-6-174G/C and increased lung cancer risk specifically in Asians. We were not able to perform an analysis for other single nucleotide polymorphisms (SNPs) as we lacked sufficient information from individual subgroups.

\section{Sensitivity analysis}

Sensitivity analysis was done for each result, reflecting the influence of the individual data set to the pooled ORs. After removing the maximum-weight study, The pooled OR remained unchanged, which indicate that high reliability in our conclusions (data not shown).

\section{Discussion}

Over the past several decades, the link between TNF- $\alpha$ and IL- 6 variations and disease has garnered increasing attention. However, the field is lacking in consistent and reliable conclusions regarding potential links between TNF- $\alpha$ and IL- 6 gene polymorphisms and lung cancer risk. Meta-analyses, however, may provide more definitive conclusions. With a large sample size and comprehensive statistical analyses, the present meta-analysis demonstrated that TNF- $\alpha-308 \mathrm{G} / \mathrm{A}$ is associated with a decreased risk of lung cancer under a dominant genetic model (GG+GA VS AA). However, our findings were not statistically significant. IL-6-174G/C polymorphisms have a slight association with an increased risk of lung cancer under the dominant genetic model. Moreover, we also detected an association between IL-6-634C/G and lung cancer risk under the recessive genetic model. Our subgroup analysis of TNF- $\alpha-308 \mathrm{G} / \mathrm{A}$ and IL-6-174G/C revealed a stronger association between these polymorphisms and lung cancer risk in Asian populations than in other races. Based on these results, the IL-6 gene may play an important role in the pathogenesis of lung cancer. However, sufficient evidence is lacking to show a more detailed relationship between these gene polymorphisms and lung cancer risk. Therefore, more original and higher quality studies regarding the association between TNF- $\alpha-308 \mathrm{G} / \mathrm{A}$, IL-6-174G/C, and IL-6-634C/G gene polymorphisms and lung cancer are essential for more accurate results.

Shih et al. [9] provided the first report of an association between TNF- $\alpha-308 \mathrm{G} / \mathrm{A}$ gene polymorphisms and the risk of non-small-cell lung cancer (NSCLC) in a Chinese population. Their methods and sample size, however, varied significantly from those of our study. Nonetheless, we drew similar conclusions to those reported by Shih et al. Specifically, we showed a weak association between TNF- $\alpha-308 \mathrm{G} / \mathrm{A}$ gene polymorphisms and lung cancer risk. TNF- $\alpha$ is a pro-inflammatory cytokine and a central mediator of the immune response involved in a wide range of inflammatory pathways and infectious diseases [21]. As TNF- $\alpha$ is closely relied upon as a defence mechanism against disease, its regulation and expression after gene conversion can become increasingly uncontrollable. Therefore, we cannot confirm that our results are entirely thorough. Further studies are needed to assess multiple 
conditions of TNF- $\alpha$ expression to validate our findings.

An autocrine or paracrine factor, IL-6 may have direct effects on tumour cells to modulate their growth. IL-6 may also indirectly promote tumour cell growth by inducing the acute phase reaction, inhibiting apoptosis and angiogenesis [22]. The $5 \mathrm{~kb}$ IL-6 gene is located on chromosome 7p21-14 and contains 4 introns and 5 exons. The promoter region contains many different regulatory elements, including transcription factor binding sites for NF-IL6, NF-KB, Fos/Jun, CRBP, glucocorticoid receptor, and others [23]. Transcription factors play a critical role in the expression of IL-6. Hence, polymorphisms in the promoter region of the IL-6 gene may cause variations in transcription, causing the gene locus to strongly impact its expression and susceptibility to diseases. Specifically, in the current meta-analysis, we found that polymorphisms of IL-6-174G/C and IL-6-634C/G were associated with the occurrence and development of lung cancer, but these connections were negligible. Thus, although our results were very different from those of previous studies, we illustrate that some connections exist between IL-6 and lung cancer. This association may become more pronounced upon further investigation.

The association of cytokine gene polymorphisms in TNF- $\alpha$ and IL- 6 with lung cancer risk has been reported in recent years. The results of our study may not be in accordance with other published findings, which may be attributed to certain limitations in the present meta-analysis. For instance, several SNPs in the TNF- $\alpha$ and IL- 6 genes have been identified. However, because TNF- $\alpha-308$ G/A, IL-6-174G/C, and IL-6-634C/G gene polymorphisms are the most widely researched, our study was limited to these three polymorphisms. Further investigation into the link between lung cancer and other TNF- $\alpha$ and IL-6 gene polymorphisms should be conducted in future studies. Additionally, the sample sizes used in our subgroup analyses were limited, making it impossible to stratify according to different tumour types. Therefore, we performed only a subgroup analysis stratifying for ethnicity. Furthermore, we could not precisely demonstrate the interactions between gene/gene and gene/environmental factors due to a lack of specific data published in each study.

\section{Conclusion}

we illustrate that TNF- $\alpha$ gene polymorphisms at position 308G/A and IL-6 gene polymorphisms at positions $174 \mathrm{G} / \mathrm{C}$ and $634 \mathrm{C} / \mathrm{G}$ have weak associations with lung cancer. However, the mechanism(s) underlying these correlations have yet to be determined [8]. We can be almost certain, however, that such occurrences in gene exchange may lead to differences in gene expression that can have an impact on lung cancer risk. To reach a more definitive conclusion, further studies are needed to assess multiple polymorphisms in the TNF- $\alpha$ and IL-6 genes. Larger sample sizes in case-control studies conducted with different pathological types to investigate the interactions between TNF- $\alpha$ and IL- 6 with other individual genes and environmental factors may further contribute to our knowledge of lung cancer pathogenesis.

\section{Abbreviations}

TNF- $\alpha$ : tumor necrosis factor-alpha; IL: Interleukin; SNPs: single nucleotide polymorphisms; EMBASE: Excerpt Medica Database; OR: odds ratio; ORs: odds ratios; CI: confidence interval; PCR: polymerase chain reaction; PCR-RFLP: polymerase chain reaction-restriction fragment length polymorphism; HWE: Hardy-Weinberg Equilibrium; F: fixed-effects model; R: random-effects model; PA: P value for test of the association; PQ: P value for between study heterogeneity; NA: not available. 


\section{Acknowledgments}

Not applicable.

\section{Authors' contributions}

SGG and XSW participated in the design of this study, YBG and YWL carried out the study and together with WS, collected important background information and drafted the manuscript. YBG, XY conceived of this study and both performed the statistical analysis and participated in the design and helped to draft the manuscript. All authors read and approved the final manuscript.

\section{Funding}

The present study was supported by The First Affiliated Hospital, and College of Clinical Medicine of Henan University of Science and Technology, Henan Province, China. The authors declare that the funding bodies have no influence on the design of the study, data collection, analysis, and interpretation of data and writing of the manuscript.

\section{Availability of data and material}

The datasets used and analyzed during the current study are available from the corresponding author on reasonable request.

\section{Ethics Approval and Consent to Participate}

All analyses were based on previous published studies, thus no ethical approval and patient consent are required.

\section{Consent for publication}

Not applicable.

\section{Competing Interest}

The authors declare that there are no conflicts of interest in this work.

\section{References}

[1] Minna JD Neoplasms of the lung. Harrison's principles of internal medicine. 14th ed. In: Fauci AS, Braunwald E, Isselbacher KJ, Wilson JD, Martin JB, Kasper DL, Hauser SL, Longo DL, editors. NewYork, McGraw-Hill; 1998. pp. 552-62.

[2] Farjadfar A, Mojtahedi Z, Ghayumi MA, Erfani N, Haghshenas MR, Ghaderi A. Interleukin-18 promoter polymorphism is associated with lung cancer: a case-control study. Acta oncologica (Stockholm, Sweden). 2009;48(7):971-6. doi:10.1080/02841860902878145.

[3] Bodelon C, Polley MY, Kemp TJ, Pesatori AC, McShane LM, Caporaso NE et al. Circulating levels of immune and inflammatory markers and long versus short survival in early-stage lung cancer. Annals of oncology : official journal of the European Society for Medical Oncology / ESMO. 2013;24(8):2073-9. doi:10.1093/annonc/mdt175.

[4] Ilonidis G, Parapanisiou E, Anogeianaki A, Giavazis I, Theofilogiannakos EK, Tsekoura P et al. Interleukin -1beta (IL-1 beta), interleukin 6 (IL-6) and tumor necrosis factor (TNF) in plasma and pleural fluid of pneumonia, lung cancer and tuberculous pleuritis. Journal of biological regulators and 
homeostatic agents. 2006;20(1-2):41-6.

[5] Wilson AG, Symons JA, McDowell TL, McDevitt HO, Duff GW. Effects of a polymorphism in the human tumor necrosis factor alpha promoter on transcriptional activation. Proceedings of the National Academy of Sciences of the United States of America. 1997;94(7):3195-9.

[6] Kiyohara C, Horiuchi T, Takayama K, Nakanishi Y. Genetic polymorphisms involved in the inflammatory response and lung cancer risk: a case-control study in Japan. Cytokine. 2014;65(1):88-94. doi:10.1016/j.cyto.2013.09.015.

[7] Seow A, Ng DP, Choo S, Eng P, Poh WT, Ming T et al. Joint effect of asthma/atopy and an IL-6 gene polymorphism on lung cancer risk among lifetime non-smoking Chinese women. Carcinogenesis. 2006;27(6):1240-4. doi:10.1093/carcin/bgi309

[8] Lim WY, Chen Y, Ali SM, Chuah KL, Eng P, Leong SS et al. Polymorphisms in inflammatory pathway genes, host factors and lung cancer risk in Chinese female never-smokers. Carcinogenesis. 2011;32(4):522-9. doi:10.1093/carcin/bgr006.

[9] Shih CM, Lee YL, Chiou HL, Chen W, Chang GC, Chou MC et al. Association of TNF-alpha polymorphism with susceptibility to and severity of non-small cell lung cancer. Lung Cancer. 2006;52(1):15-20. doi:10.1016/j.lungcan.2005.11.01.

[10] Shukla RK, Kant S, Bhattacharya S, Mittal B. Association of Cytokine Gene Polymorphisms in Patients with Chronic Obstructive Pulmonary Disease. Oman Med J. 2012;27(4):285-90. doi:10.5001/omj.2012.71.

[11] Flego V, Radojcic Badovinac A, Bulat-Kardum L, Matanic D, Crnic-Martinovic M, Kapovic M et al. Primary lung cancer and TNF-alpha gene polymorphisms: a case-control study in a Croatian population. Med Sci Monit. 2009;15(7):Cr361-5.

[12] Flego V, Ristić S, Pavlić SD, Lender DM, Bulat-Kardum L, Kapović M et al. Tumor necrosis factor-alpha gene promoter -308 and -238 polymorphisms in patients with lung cancer as a second primary tumor. Med Sci Monit. 2013;19:846-51. doi:10.12659/msm.889554.

[13] Reyes-Gibby CC, Spitz M, Wu X, Merriman K, Etzel C, Bruera E et al. Cytokine genes and pain severity in lung cancer: exploring the influence of TNF-alpha-308 G/A IL6-174G/C and IL8-251T/A. Cancer epidemiology, biomarkers \& prevention : a publication of the American Association for Cancer Research, cosponsored by the American Society of Preventive Oncology. 2007;16(12):2745-51. doi:10.1158/1055-9965.epi-07-0651.

[14] Seifart C, Plagens A, Dempfle A, Clostermann U, Vogelmeier C, von Wichert P et al. TNF- $\alpha$, TNF- $\beta$, IL-6, and IL-10 Polymorphisms in Patients with Lung Cancer. Disease Markers. 2005;21(3):157-65. doi:10.1155/2005/707131.

[15] Stankovic MM, Nestorovic AR, Tomovic AM, Petrovic-Stanojevic ND, Andjelic-Jelic MS, Dopudja-Pantic VB et al. TNF-alpha-308 promotor polymorphism in patients with chronic obstructive pulmonary disease and lung cancer. Neoplasma. 2009;56(4):348-52.

[16] Küçükaycan M, Van Krugten M, Pennings HJ, Huizinga TW, Buurman WA, Dentener MA et al. Tumor Necrosis Factor- $\alpha+489 \mathrm{G} / \mathrm{A}$ gene polymorphism is associated with chronic obstructive pulmonary disease. Respir Res. 2002;3(1):29. doi:10.1186/rr194.

[17] Reyes-Gibby CC, Spitz MR, Yennurajalingam S, Swartz M, Gu J, Wu X et al. The role of inflammation gene polymorphisms on pain severity in lung cancer patients. Cancer Epidemiol Biomarkers Prev. 2009;18(10):2636-42. doi:10.1158/1055-9965.epi-09-0426.

[18] Kaabachi S, Kaabachi W, Rafrafi A, Belkis H, Hamzaoui K, Sassi FH. Tumor necrosis factor gene polymorphisms in Tunisian patients with non-small cell lung cancer. Clin Lab. 
2013;59(11-12):1389-95.

[19] Kiyohara C, Horiuchi T, Takayama K, Nakanishi Y. Genetic polymorphisms involved in the inflammatory response and lung cancer risk: a case-control study in Japan. Cytokine. 2014;65(1):88-94. doi:10.1016/j.cyto.2013.09.015.

[20] Vogel U, Christensen J, Wallin H, Friis S, Nexo BA, Raaschou-Nielsen O et al. Polymorphisms in genes involved in the inflammatory response and interaction with NSAID use or smoking in relation to lung cancer risk in a prospective study. Mutation research. 2008;639(1-2):89-100. doi:10.1016/j.mrfmmm.2007.11.004.

[21] Beutler BA. The role of tumor necrosis factor in health and disease. The Journal of rheumatology Supplement. 1999;57:16-21.

[22] Bai L, Yu H, Wang H, Su H, Zhao J, Zhao Y. Genetic single-nucleotide polymorphisms of inflammation-related factors associated with risk of lung cancer. Medical oncology. 2013;30(1):414. doi:10.1007/s12032-012-0414-6.

[23] Akira S, Taga T, Kishimoto T. Interleukin-6 in biology and medicine. Advances in immunology. 1993;54:1-78. 
Figures

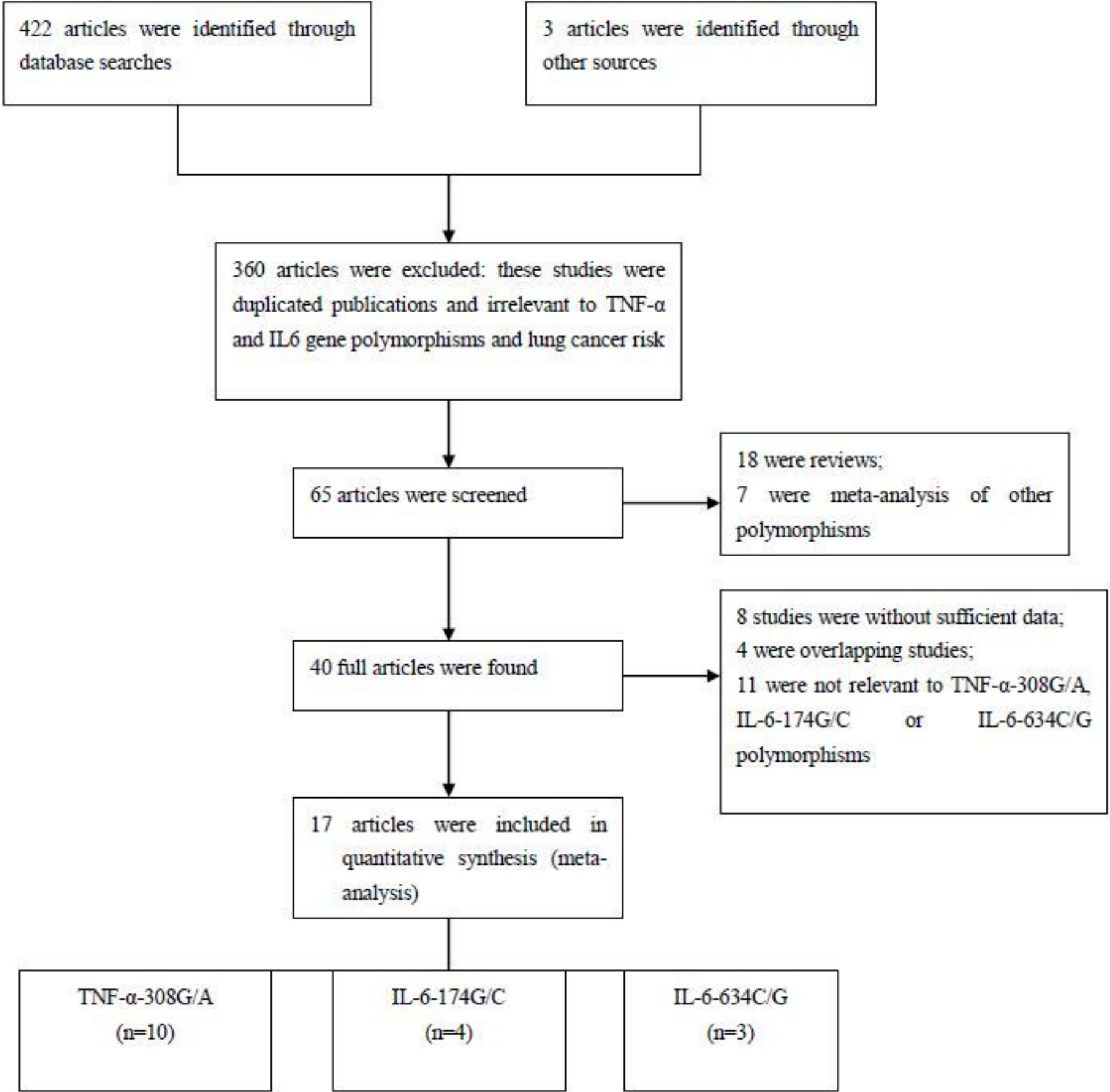

\section{Figure 1}

Flow chart for literature screening. TNF-a: tumor necrosis factor-alpha; IL: Interleukin. 


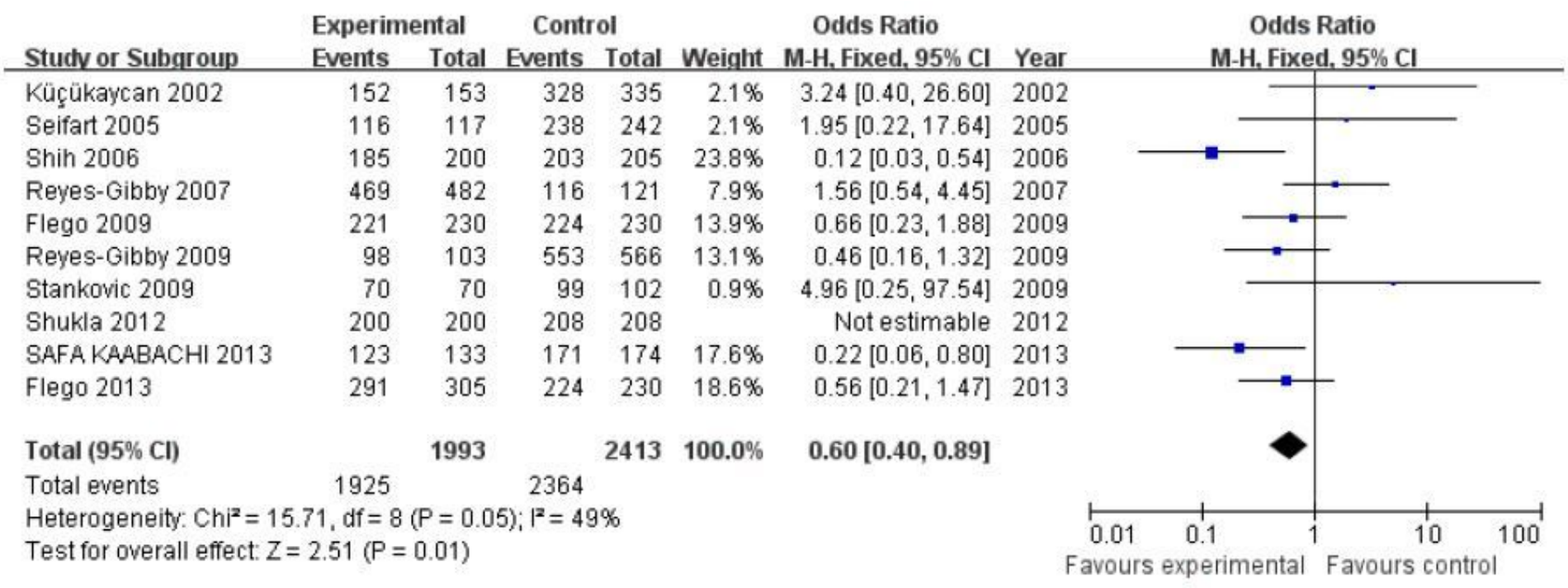

Figure 2

Forest plots of the association between the TNF a 308G/A gene polymorphisms and risk of lung cancer under dominant model (contrast GG + GA vs. AA). OR: odds ratio; Cl: confidence interval TNF a: tumor necro sis factor alpha.

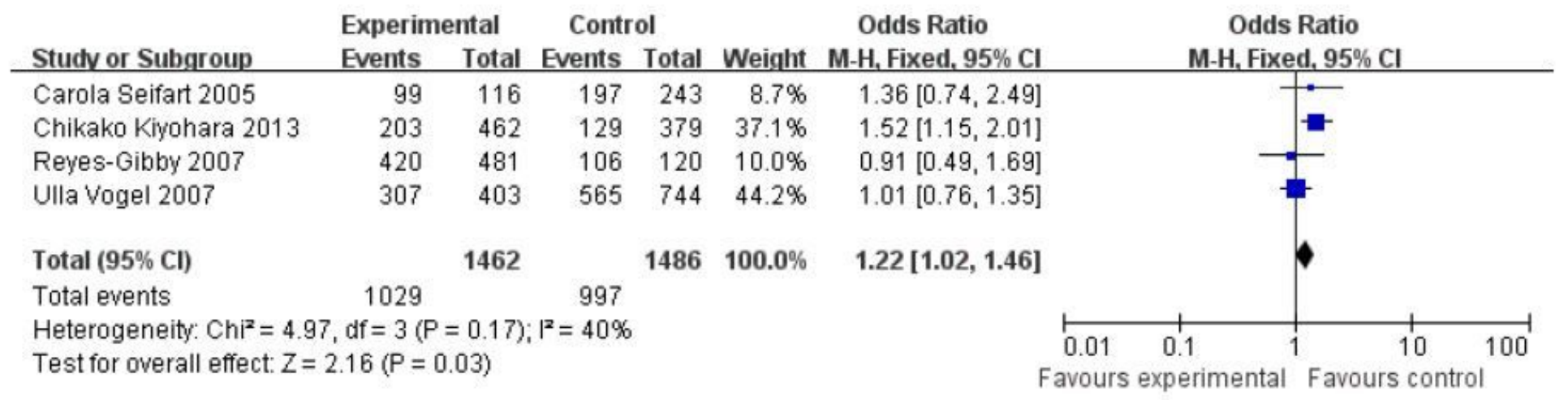

\section{Figure 3}

Forest plots of the association between the IL 6 174G/C gene polymorphisms and risk of lung cancer under dominant model (contrast GG+GC vs. CC OR: odds ratio; Cl: confidence interval IL : Inter leukin

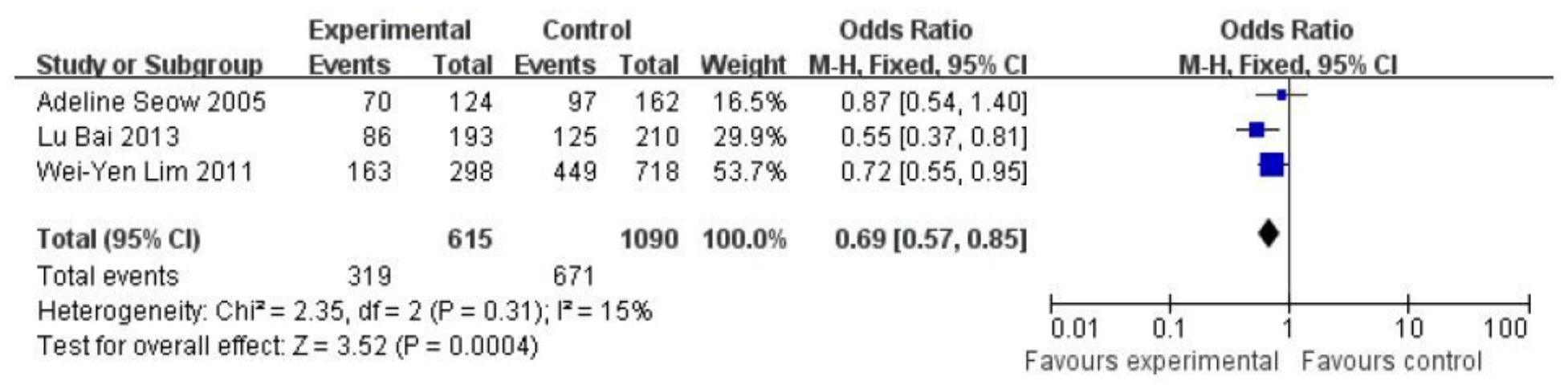


Figure 4

Forest plots of the association between the IL $6634 \mathrm{C} / \mathrm{G}$ gene polymorphisms and risk of lung cancer under reces sive model (contrast CC vs. CG + GG OR: odds ratio; Cl: confidence interval IL Interleukin 